\title{
(6) OPEN ACCESS \\ Drug survival on TNF inhibitors in patients with rheumatoid arthritis comparison of adalimumab, etanercept and infliximab
}

\author{
M Neovius, ${ }^{1}$ E V Arkema, ${ }^{1}$ H Olsson, ${ }^{1}$ J K Eriksson, ${ }^{1}$ L E Kristensen, ${ }^{2}$ J F Simard, ${ }^{1}$ \\ J Askling, ${ }^{1,3}$ for the ARTIS Study Group
}

\begin{abstract}
Handling editor Tore K Kvien
- Additional material is published online only. To view please visit the journal online (http://dx.doi.org/10.1136/ annrheumdis-2013-204128)

${ }^{1}$ Clinical Epidemiology Unit, Department of Medicine, Karolinska Institutet, Stockholm, Sweden ${ }^{2}$ Department of Rheumatology, Lund University, Lund, Sweden ${ }^{3}$ Rheumatology Unit, Department of Medicine, Karolinska Institutet, Stockholm, Sweden
\end{abstract}

\section{Correspondence to} Dr Martin Neovius, Clinical Epidemiology Unit (T2), Department of Medicine (Solna), Karolinska Institutet, Stockholm SE-171 76, Sweden; martin.neovius@ki.se

Received 17 June 2013 Revised 25 August 2013 Accepted 3 November 2013 Published Online First 27 November 2013

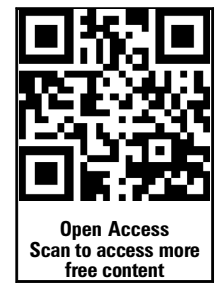

CrossMark

To cite: Neovius $M$, Arkema EV, Olsson $\mathrm{H}$, et al. Ann Rheum Dis

2015;74:354-360.

\section{ABSTRACT}

Objective To compare drug survival on adalimumab, etanercept and infliximab in patients with rheumatoid arthritis (RA).

Methods Patients with RA ( $n=9139 ; 76 \%$ women; mean age 56 years) starting their first tumour necrosis factor (TNF) inhibitor between 2003 and 2011 were identified in the Swedish Biologics Register (ARTIS). Data were collected through 31 December 2011. Drug survival over up to 5 years of follow-up was compared overall and by period of treatment start (2003-2005/ 2006-2009; $n=3168 / 4184$ ) with adjustment for age, sex, education, period, health assessment questionnaire (HAQ), disease duration, concomitant disease modifying antirheumatic drug (DMARD) treatment and general frailty (using hospitalisation history as proxy).

Results During 20198 person-years (mean/median 2.2/ 1.7 years) of follow-up, 3782 patients discontinued their first biological (19/100 person-years; $51 \%$ due to inefficacy, $36 \%$ due to adverse events). Compared with etanercept, infliximab (adjusted HR 1.63, 95\% Cl 1.51 to 1.77) and adalimumab initiators had higher discontinuation rates $(1.26,95 \% \mathrm{Cl} 1.16$ to 1.37$)$, and infliximab had a higher discontinuation rate than adalimumab $(1.28,95 \% \mathrm{Cl} 1.18$ to 1.40$)$. These findings were consistent across periods, but were modified by time for adalimumab versus etanercept ( $p<0.001$; betweendrug difference highest the 1st year in both periods). The discontinuation rate was higher for starters in 2006-2009 than 2003-2005 (adjusted HR 1.12, 95\% Cl 1.04 to 1.20). The composition of 1 -year discontinuations also changed from 2003-2005 vs 2006-2009: adverse events decreased from $45 \%$ to $35 \%$, while inefficacy increased from $43 \%$ to $53 \%(p<0.001)$.

Conclusions Discontinuation rates were higher for infliximab compared with adalimumab and etanercept initiators, and for adalimumab versus etanercept during the 1st year. Discontinuation rates increased with calendar period, as did the percentage discontinuations due to inefficacy.

\section{INTRODUCTION}

Drug survival can be interpreted as a composite measure of effectiveness, safety and tolerability since the most common reasons for discontinuation of tumour necrosis factor (TNF) inhibitors (TNFi) have been reported to be lack/loss of efficacy and adverse events. ${ }^{1-8}$ However, drug survival may also be influenced by other factors, such as the number of alternative treatment options available and the characteristics of the patient population treated, both of which have changed over time. ${ }^{3} 49-11$

Previous studies from Sweden, ${ }^{4}$ Spain, ${ }^{5}$ Switzerland ${ }^{1}$ and the USA ${ }^{12}$ have shown decreasing 1-year TNFi drug survival since their introduction in the late 1990s. Danish and British data, on the other hand, showed a relatively stable TNFi discontinuation rate between 2000-2005 and 2001-2008, respectively. ${ }^{3} 10$ During the last 10 years, characteristics of the TNFi patient population have changed, with patients today generally having lower disease activity and higher functional ability at initiation. 3 9-11 which in some studies have been associated with better drug survival. ${ }^{1} 1314$ At the same time, the penetration of TNFi treatment has increased dramatically, the number of alternative biological drugs has increased, as have expectations of better treatment outcomes.

Some studies have compared drug survival on etanercept, adalimumab and infliximab. Six European studies 127131516 found infliximab patients to have shorter time on drug than adalimumab and/or etanercept initiators, while five other European studies found no between-drug differences. ${ }^{8} 14$ 17-19 Two US studies have reported the opposite with longer time on infliximab compared with etanercept and adalimumab. ${ }^{12} 20$ Most of these studies included the period when there was a shortage of etanercept (2000-2003) and when adalimumab was not yet on the market (before 2003; see online supplementary eTables 1-3). No study has investigated whether potential between-drug differences are constant over follow-up time, or restricted to the initial period of follow-up, nor investigated whether there are calendar period differences during the period when all three drugs were on the market.

We hypothesised that drug discontinuation rates differed between adalimumab, etanercept and infliximab, that these differences were modified by time, and that TNFi discontinuation rates have changed across calendar periods. Therefore the aim of this study was to compare between-group discontinuation rates for adalimumab, etanercept and infliximab in a large population-based cohort of patients with rheumatoid arthritis (RA) starting their first TNFi during the period when adalimumab, etanercept and infliximab all were available on the market (2003-2011) in a setting with relatively equal access to each drug. As secondary aims, calendar period changes in discontinuation rates (2003-2005 vs 2006-2009) and predictors of discontinuation were investigated. 


\section{METHODS}

Swedish healthcare is publicly available and tax funded. Treatment is provided predominantly by rheumatologists with the treatment decision residing with the treating rheumatologists, and regional practice differences exist. ${ }^{21}$ Access to biologicals is not limited by any application process, disease activity cut-offs or similar thresholds. Estimates suggest that $16-20 \%$ of patients with RA were receiving biological therapy in 2008, but with large age variations (eg, $>30 \%$ in working age patients). ${ }^{22}$

\section{Data source}

The Swedish Biologics Register (ARTIS) was established in conjunction with the introduction of biologicals, and has been described elsewhere. ${ }^{4} 23$ Briefly, the register is overseen by the Swedish Rheumatology Association and is integrated into clinical practice. Disease activity and treatment is registered at biological initiation and at regular follow-up visits by the treating rheumatologists. Estimates suggest that ARTIS covers $87 \%$ of all patients with RA treated with biologicals. ${ }^{24}$ For this study, patients with RA $\geq 16$ years initiating their first TNFi therapy between 1 January 2003 and 31 December 2011, were included. The RA diagnoses were registered according to the assessment of the treating rheumatologists, which for most of the period would be consistent with the American College of Rheumatology (ACR) 1987 criteria.

\section{Treatment and covariates}

For each patient, data on first treatment with adalimumab, etanercept and infliximab were collected, as were data on age, sex, education level, disease duration, health assessment questionnaire (HAQ), disease activity score 28 (DAS28) and concomitant treatment. The number of hospital days and non-primary outpatient care visits due to any cause during the previous 2 years were used as two separate measures of general patient frailty. These data were collected from the Swedish National Patient Register kept by the National Board of Health and Welfare.

\section{Outcome and follow-up}

The primary outcome was discontinuation of biological therapy due to any cause, except for pregnancy and remission. Remission was registered according to the treating rheumatologists' assessment of disease activity rather than strictly defined by, for example, DAS28.

Patients were followed for a maximum of 5 years from time of TNFi initiation until discontinuation, death, end of follow-up (31 December 2011), discontinuation due to pregnancy or remission, or when patients had not had a clinical visit in 450 days (patients assumed lost to follow-up), whichever came first. Data were also collected on reason for discontinuation as reported by the treating rheumatologist for the following prespecified and mutually exclusive categories: lack/loss of efficacy, adverse event or other. As a secondary outcome, calendar period changes in discontinuation rates were investigated, comparing 2003-2005 with 2006-2009. Also, predictors of discontinuations were investigated, including age, sex, education level, HAQ, disease duration, calendar period of initiation, concomitant treatment and general frailty.

\section{Statistics}

Drug-specific and calendar period-specific crude discontinuation rates were calculated per 100 person-years, and presented using Kaplan-Meier curves. The share stopping due to adverse event or lack/loss of efficacy, along with 1-year risks of discontinuing first biological treatment were calculated.
Cox regression was used to estimate hazard ratios (HRs) for discontinuation. First, predictors of discontinuation were investigated using univariable and multivariable models, stratified by drug. Second, HRs were estimated for adalimumab versus etanercept, infliximab versus etanercept and infliximab versus adalimumab. These latter models were conditioned on age, sex and calendar period, and adjusted for baseline HAQ, disease duration, concomitant treatment with non-biological disease modifying antirheumatic drugs (DMARDs), education level and general frailty, as many of these factors have been shown to influence drug survival. $^{1}{ }^{13-15}$ For effects that were modified by time, time-on-treatment specific HRs were calculated within subsets of the total follow-up time (0-1 year, 1-1.9 years, 2-5 years). Missing data were handled using the missing indicator method.

Statistical analyses were performed using SAS statistical software (V.9.2) and Stata (V.11). A p value of $<0.05$ was considered statistically significant, and the proportional hazards assumption was tested by including an interaction term between biological drug and observation time.

\section{RESULTS}

\section{Patient characteristics}

A total of 9139 patients with RA initiating TNFi as their first ever biological between 2003 and 2011 were identified, with $26 \%$ starting adalimumab, 43\% etanercept and 32\% infliximab (table 1). Overall, $76 \%$ were women, the mean age was 56 years and the median disease duration 8 years.

Of patients with registered DAS28 at baseline $(\mathrm{n}=7751 ; 85 \%)$, $50 \%$ had high (DAS28 $\geq 5.2$ ), 40\% moderate (DAS28 $=3.2-5.1$ ) and $9.0 \%$ low disease activity (DAS28 $<3.2$; table 1 ). A statistically significant difference in disease activity existed between initiators of the different drugs, but was numerically small ( $\leq 0.1$ units). Statistically significant differences also existed for age, sex, rheumatoid factor status, HAQ, disease duration and general patient frailty measured by hospital days and non-primary outpatient care visits in the past 2 years, but were generally of small magnitude (table 1). The share of patients without concomitant DMARDs was lower in infliximab (12\%) than adalimumab (24\%) and etanercept initiators $(28 \% ; \mathrm{p}<0.001)$.

\section{Events and follow-up}

During 20198 person-years of follow-up, 3782 patients discontinued their first biological (table 2). The most common cause for discontinuation over the full period was lack/loss of efficacy (51\%), followed by adverse events (36\%), with similar distributions seen across adalimumab, etanercept and infliximab initiators (table 2).

\section{Biological drug and discontinuation}

In unadjusted analyses and compared with etanercept, higher discontinuation rates were observed for infliximab (HR 1.56, 95\% CI 1.45 to 1.68 ) and adalimumab initiators (HR 1.22, 95\% CI 1.13 to 1.33$)$. Infliximab initiators also had a higher rate than adalimumab initiators (HR 1.26, 95\% CI 1.16 to 1.37 ).

After 0.8 years, $25 \%$ of patients had discontinued among adalimumab and infliximab initiators, while the same percentage of patients had discontinued etanercept after 1.3 years (figure 1). Fifty per cent of infliximab initiators had discontinued drug after 2.6 years, while $50 \%$ of adalimumab users had discontinued after 5.0 years. At the end of the 5 -year follow-up $38 \%$ of infliximab, $50 \%$ of adalimumab and $55 \%$ of etanercept initiators remained on their first drug.

The interdrug associations remained after adjustment (figure 1). However, the proportional hazards assumption was violated for 
Table 1 Patient characteristics at initiation of first TNF inhibitor between 2003 and 2011 in 9139 Swedish patients with rheumatoid arthritis*

\begin{tabular}{|c|c|c|c|c|}
\hline & Etanercept $(n=3892)$ & Adalimumab $(n=2349)$ & Infliximab $(n=2898)$ & p Valuet \\
\hline \multicolumn{5}{|l|}{ Sex, n (\%) } \\
\hline Women & $2995(77 \%)$ & $1766(75 \%)$ & $2151(74 \%)$ & 0.03 \\
\hline \multicolumn{5}{|l|}{ Age (years) } \\
\hline Mean (SD) & $55.1(13.7)$ & $55.7(13.3)$ & $56.7(13.1)$ & $<0.001$ \\
\hline \multicolumn{5}{|c|}{ Rheumatoid factor status, n (\%) } \\
\hline Positive & $496(74 \%)$ & $267(76 \%)$ & $389(75 \%)$ & $<0.001$ \\
\hline Negative & $2082(18 \%)$ & $1301(16 \%)$ & $1563(18 \%)$ & \\
\hline Unspecified & $281(8.3 \%)$ & 146 (8.0\%) & $132(7.2 \%)$ & \\
\hline \multicolumn{5}{|l|}{ HAQ, n (\%) } \\
\hline Mean (SD) & $1.15(0.64)$ & $1.15(0.65)$ & $1.20(0.64)$ & 0.002 \\
\hline$<1.00$ & $1334(34 \%)$ & $811(35 \%)$ & $895(31 \%)$ & $<0.001$ \\
\hline $1.00-1.49$ & $1048(27 \%)$ & $623(27 \%)$ & 727 (25\%) & \\
\hline $1.5-1.99$ & $656(17 \%)$ & $419(18 \%)$ & $536(18 \%)$ & \\
\hline$\geq 2.00$ & $452(12 \%)$ & $273(12 \%)$ & $360(12 \%)$ & \\
\hline Missing & $402(10 \%)$ & $223(9.5 \%)$ & $380(13 \%)$ & \\
\hline \multicolumn{5}{|l|}{ DAS28, n (\%) } \\
\hline Mean (SD) & $5.1(1.4)$ & $5.1(1.4)$ & $5.2(1.4)$ & 0.004 \\
\hline$<3.2$ & $318(8.2 \%)$ & $176(7.5 \%)$ & $207(7.1 \%)$ & $<0.01$ \\
\hline $3.2-5.1$ & $1371(35 \%)$ & $832(35 \%)$ & $935(32 \%)$ & \\
\hline$\geq 5.2$ & $1617(42 \%)$ & $1019(43 \%)$ & $1276(44 \%)$ & \\
\hline Missing & $586(15 \%)$ & $322(14 \%)$ & $480(17 \%)$ & \\
\hline \multicolumn{5}{|c|}{ Disease duration (years), $\mathrm{n}(\%)$} \\
\hline Mean (SD) & $12(14)$ & $13(16)$ & $13(17)$ & $<0.01$ \\
\hline Median (p25-75) & $7(3-16)$ & $8(3-17)$ & $8(3-16)$ & \\
\hline$<1$ year & $259(6.7 \%)$ & $143(6.1 \%)$ & $251(8.7 \%)$ & 0.002 \\
\hline $1-4.9$ year & $1218(31 \%)$ & $681(29 \%)$ & $870(30 \%)$ & \\
\hline $5-9.9$ year & $794(20 \%)$ & $468(20 \%)$ & $559(19 \%)$ & \\
\hline$\geq 10$ & $1579(41 \%)$ & $1022(44 \%)$ & $1187(41 \%)$ & \\
\hline Missing & $113(1.1 \%)$ & 35 (1.5\%) & $31(1.1 \%)$ & \\
\hline \multicolumn{5}{|l|}{ TNF inhibitors, n (\%) } \\
\hline $2003-2005$ & $1240(39 \%)$ & $852(27 \%)$ & $1076(34 \%)$ & $<0.001$ \\
\hline $2006-2009$ & $1915(46 \%)$ & $1041(25 \%)$ & $1228(29 \%)$ & \\
\hline 2010-2011 & $737(41 \%)$ & $456(26 \%)$ & $594(33 \%)$ & \\
\hline \multicolumn{5}{|c|}{ Concomitant DMARDs, n (\%) } \\
\hline No & $1072(28 \%)$ & $561(24 \%)$ & $335(12 \%)$ & $<0.001$ \\
\hline MTX & $2267(58 \%)$ & $1443(61 \%)$ & $2162(75 \%)$ & \\
\hline Other & $553(14 \%)$ & $345(15 \%)$ & $401(14 \%)$ & \\
\hline \multicolumn{5}{|l|}{ Hospital days $\ddagger$} \\
\hline Mean (SD) & $4(13)$ & $4(11)$ & $5(14)$ & 0.002 \\
\hline Median (p25-75) & $0(0-3)$ & $0(0-3)$ & $0(0-4)$ & \\
\hline \multicolumn{5}{|l|}{ Outpatient visits $¥$} \\
\hline Mean (SD) & $11(9)$ & $9(8)$ & $10(8)$ & $<0.001$ \\
\hline Median (p25-75) & $9(5-15)$ & $7(4-13)$ & $8(4-13)$ & \\
\hline
\end{tabular}

${ }^{*}$ p25-75=25th to 75 th centile.

tCalculated using ANOVA with Bonferroni correction.

$¥$ Assessed during the 2 years preceding TNFi treatment initiation. Data on hospital days and non-primary outpatient care visits retrieved from the Swedish National Patient Register between 2001 and 2009, and include admissions and visits due to any cause.

ACR, American College of Rheumatology; ANOVA, analysis of variance; DAS28, disease activity score 28 joint count; DMARD, disease modifying antirheumatic drug; HAQ, health assessment questionnaire; MTX, methotrexate; TNF, tumour necrosis factor; TNFi, TNF inhibitor.

adalimumab versus etanercept (higher HR only during the 1 st year) and infliximab (no difference during the 1 st year; time $\times$ drug interaction, $\mathrm{p}<0.001$ for both). For infliximab versus etanercept, and infliximab versus adalimumab initiators, statistically significantly greater discontinuation rates were seen over the 1 st (only vs etanercept), 2 nd and 3 rd to 5 th years (figure 1 ).

\section{Predictors of discontinuation}

In adjusted analyses in strata defined by biological drug, greater discontinuation rates were observed in women than in men, in patients with lower education compared with higher education, in the 2006-2009 and 2010-2011 vs the 2003-2005 periods, in patients with higher baseline HAQ and in patients with greater general frailty (table 3). Concomitant DMARD treatment and longer disease duration were associated with lower risk of discontinuation.

\section{Calendar period and discontinuation}

The discontinuation rate was greater for starters in 2006-2009 than 2003-2005 (adjusted HR 1.12, 95\% CI 1.04 to 1.20); 
Table 2 Discontinuations, person-years and incidence rates over up to 5 years of follow-up in Swedish patients with rheumatoid arthritis starting their first TNFi between 2003 and 2011

\begin{tabular}{|c|c|c|c|c|}
\hline & Etanercept $(n=3892)$ & Adalimumab $(n=2349)$ & Infliximab $(n=2898)$ & Total $(n=9139)$ \\
\hline Observation years & 9259 & 5131 & 5808 & 20198 \\
\hline Discontinuations, $\mathrm{n}(\%)$ & $1391(100 \%)$ & $963(100 \%)$ & $1470(100 \%)$ & $3782(100 \%)$ \\
\hline Lack/loss of efficacy* & $710(51 \%)$ & $476(49 \%)$ & $738(52 \%)$ & $1924(51 \%)$ \\
\hline Adverse event & $474(34 \%)$ & $349(36 \%)$ & $525(37 \%)$ & $1348(36 \%)$ \\
\hline Other & $207(15 \%)$ & $138(14 \%)$ & $165(12 \%)$ & $510(13 \%)$ \\
\hline \multicolumn{5}{|c|}{ Discontinuation causes not counted as events, $\mathrm{n}(\%)$} \\
\hline Pregnancy & $59(1.5 \%)$ & $15(0.6 \%)$ & $12(0.4 \%)$ & $86(0.9 \%)$ \\
\hline Remissiont & $44(1.1 \%)$ & $53(2.3 \%)$ & $50(1.7 \%)$ & $147(1.6 \%)$ \\
\hline Death & $31(0.8 \%)$ & $30(1.3 \%)$ & $35(1.2 \%)$ & $96(1.1 \%)$ \\
\hline Incidence per 100 person-years & 15 & 19 & 25 & 19 \\
\hline \multicolumn{5}{|l|}{1 year drug survival } \\
\hline Observation years, sum & 2355 & 1349 & 1667 & 5371 \\
\hline Discontinuations, $\mathrm{n}$ & 671 & 517 & 668 & 1856 \\
\hline$\%$ & $26 \%$ & $34 \%$ & $36 \%$ & $31 \%$ \\
\hline
\end{tabular}

figure 2). The composition of 1-year discontinuations also changed with adverse events decreasing from $45 \%$ to $35 \%$, while lack/loss of efficacy increased from $43 \%$ to $53 \%$ $(\mathrm{p}<0.001)$.

\section{DISCUSSION}

We compared discontinuation rates on adalimumab, etanercept and infliximab in the largest sample to date of patients with RA initiating treatment between 2003 and 2011, a period when all three drugs were available. We found that discontinuation rates were higher for infliximab compared with adalimumab and etanercept initiators, and for adalimumab versus etanercept during the 1 st year. Half of all initiators had discontinued infliximab after 2.6 years compared with 5.0 years of adalimumab initiators, and at the end of the 5 -year follow-up 38\% of infliximab, $50 \%$ of adalimumab and $55 \%$ of etanercept initiators remained on their first drug. There was a calendar period trend with greater discontinuation rates in patients starting TNFi treatment in 2006-2009 compared with 2003-2005, and there was an increasing percentage quitting (or switching) biologicals due to lack/loss of efficacy and a decreasing percentage due to adverse events.

\section{Previous research}

Most previous studies have included the period during which there were supply problems with etanercept and when adalimumab was not yet on the market (see online supplementary eTables 1-3). The only study starting follow-up in 2003, as our study, showed etanercept and adalimumab to be superior to infliximab in terms of drug survival in unadjusted analyses of 916 patients, but no difference between adalimumab and etanercept. ${ }^{2}$ A large study from Denmark, which adjusted for many prognostic factors, also found infliximab to have the shortest drug survival and reported that patients on etanercept had greater drug survival than patients on adalimumab. We found that the relationship between adalimumab versus etanercept and infliximab varied over time, with a greater HR versus etanercept only during the 1 st year, and no difference versus infliximab during the 1 st year. No previous study appears to have reported
Figure 1 Drug survival on etanercept, adalimumab and infliximab. Hazard ratio adjusted for age, sex, period, education level, baseline $H A Q$, disease duration, concomitant DMARD, and general frailty.

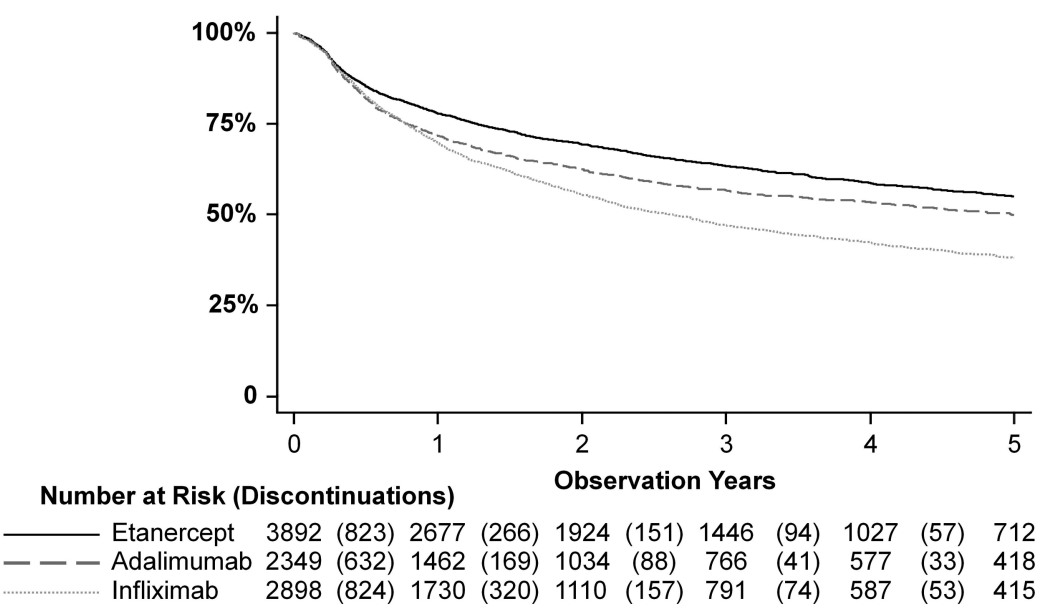

Number at Risk (Discontinuations)
$2-5 y$
$1.00(.84-1.20)$

$1.70(1.46-1.99)$

$\begin{array}{ccc}\text { Adj. Hazard Ratios }(\mathbf{9 5} \% \mathrm{Cl}) & 0-1 \mathrm{y} & >1-1.9 \mathrm{y} \\ \text {-Adalimumab vs Etanercept } & 1.37(1.23-1.52) & 1.18(.97-1.44)\end{array}$

- Infliximab vs Etanercept $1.48(1.34-1.64) \quad 2.02(1.70-2.40)$

$\begin{array}{lll}\text {-Infliximab vs Adalimumab } & 1.10(.99-1.23) & 1.65(1.36-2.00)\end{array}$ 
Table 3 Predictors of first TNFi discontinuation over a maximum of 5 years of follow-up in 9139 Swedish patients with rheumatoid arthritis*

\begin{tabular}{|c|c|c|c|c|}
\hline & Unadjusted HR $(95 \% \mathrm{CI})$ & $p$ Value & Adjusted HR (95\% Cl) & $\mathrm{p}$ Value \\
\hline Age (per 10 years) & $1.06(1.03$ to 1.08$)$ & $<0.001$ & $1.02(0.99$ to 1.05$)$ & 0.13 \\
\hline Women & $1.16(1.07$ to 1.25$)$ & $<0.001$ & $1.12(1.04$ to 1.21$)$ & 0.004 \\
\hline Men & 1.00 (ref) & & 1.00 (ref) & \\
\hline \multicolumn{5}{|l|}{ Education level } \\
\hline$<9$ years & 1.20 (1.10 to 1.32$)$ & $<0.001$ & 1.14 (1.04 to 1.25$)$ & $<0.001$ \\
\hline $10-12$ years & $1.22(1.12$ to 1.32$)$ & $<0.001$ & $1.20(1.10$ to 1.30$)$ & \\
\hline$>12$ years & 1.00 (ref) & & 1.00 (ref) & \\
\hline Missing & $1.15(0.91$ to 1.46$)$ & 0.23 & 1.06 (0.83 to 1.34$)$ & \\
\hline \multicolumn{5}{|l|}{ Period } \\
\hline 2003-2005 & 1.00 (ref) & 0.15 & 1.00 (ref) & $<0.001$ \\
\hline 2006-2009 & $1.06(0.99$ to 1.14$)$ & & $1.13(1.06$ to 1.21$)$ & \\
\hline 2010-2011 & 1.09 (0.98 to 1.21$)$ & & $1.20(1.10$ to 1.30$)$ & \\
\hline $\mathrm{HAQ}$ at baseline & & $<0.001$ & & $<0.001$ \\
\hline$<1$ & 1.00 (ref) & & 1.00 (ref) & \\
\hline $1-1.49$ & 1.21 (1.11 to 1.32$)$ & & $1.19(1.09$ to 1.30$)$ & \\
\hline $1.5-1.9$ & 1.29 (1.18 to 1.42$)$ & & $1.22(1.11$ to 1.34$)$ & \\
\hline$\geq 2$ & $1.42(1.28$ to 1.57$)$ & & $1.26(1.13$ to 1.41$)$ & \\
\hline Missing & 1.09 (0.97 to 1.22$)$ & & 0.97 (0.86 to 1.09 ) & \\
\hline \multicolumn{5}{|l|}{ Concomitant drug use } \\
\hline Non-biological DMARDs & 0.78 (0.72 to 0.84$)$ & $<0.001$ & 0.78 (0.72 to 0.84$)$ & $<0.001$ \\
\hline No non-biological DMARDs & 1.00 (ref) & & 1.00 (ref) & \\
\hline \multicolumn{5}{|l|}{ General patient frailty $\dagger$} \\
\hline Hospital days (per 10) & 1.07 (1.04 to 1.09$)$ & $<0.001$ & 1.04 (1.01 to 1.06$)$ & 0.002 \\
\hline Outpatient visits (per 10) & 1.14 (1.10 to 1.18$)$ & $<0.001$ & $1.13(1.09$ to 1.17$)$ & $<0.001$ \\
\hline
\end{tabular}

whether discontinuation rates between the respective drugs change over time on treatment.

In contrast with most European studies which show shorter drug survival on infliximab compared with adalimumab and/or etanercept, US studies have shown the opposite. ${ }^{12} 20$ Biological initiators as a group in the USA have been shown to have much lower disease activity at initiation compared with European patients, and infliximab users have been reported to be treated with higher doses than in Europe. ${ }^{20}$ Another factor potentially affecting drug survival is that Medicare has reimbursed the cost

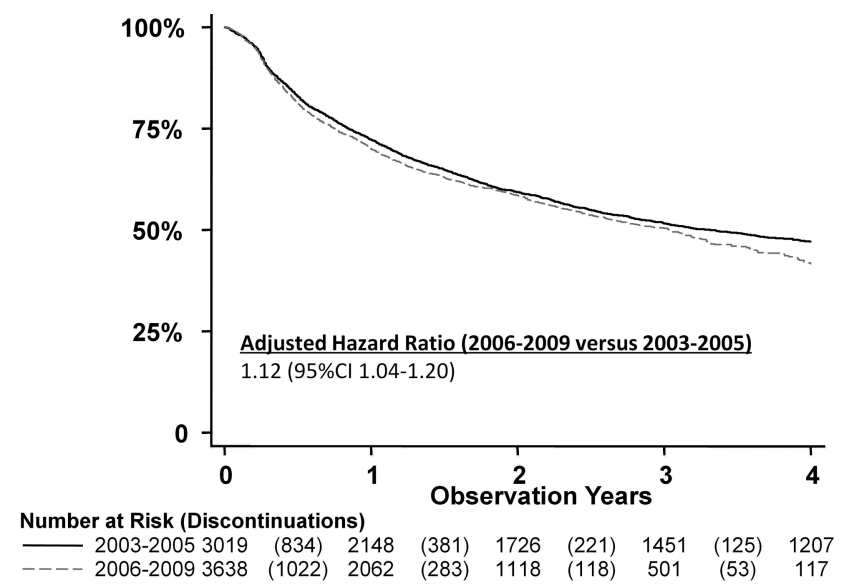

Figure 2 Drug survival by TNF inhibitor initiation period. Hazard ratio adjusted for biologic drug, age, sex, period, education level, baseline $H A Q$, disease duration, concomitant DMARD, and general frailty. of infliximab as an intravenous infusion, while not reimbursing adalimumab and etanercept which are subcutaneous self-injections. $^{25}$

While British and Danish studies have not shown any change in drug survival over time, ${ }^{3}{ }^{10}$ we found significantly higher discontinuation rates in the 2006-2009 period compared with the 2003-2005 period. This difference was strengthened by adjustment for prognostic factors at baseline, which have improved over time in several countries, ${ }^{3} 4^{9-11}$ and have been associated with improved drug survival in previous studies ${ }^{114}$ as well as in our current study.

\section{Underlying mechanisms}

Our study and several previous European studies have shown greater discontinuation rates for infliximab than adalimumab and/or etanercept, ${ }^{12} 713$ although this is not a universal finding in Europe. ${ }^{8} \quad 14{ }^{17-19}$ An increased risk of discontinuation of infliximab may be explained partly by adverse events due to infusion reactions which can only be experienced by infliximab users. ${ }^{1} 813$ Also, the chimerical structure with a murine component in infliximab may contribute via greater immunogenicity. However, Hetland et al found infliximab to have greater drug discontinuation rates compared with etanercept due to adverse events and lack of efficacy after multivariable adjustment. ${ }^{7}$ Others have reported the greater discontinuation rates on infliximab to be driven only by adverse events, specifically infusion and systemic allergic reactions. ${ }^{1} 13$

Another contributing factor may be channelling of a certain type of patients to infliximab, for example patients who are either expected to have problems with self-administration of 
non-infusion biologicals, or patients for whom the treating rheumatologist may want to have more regular clinic-based check-ups.

Apart from the differential risk of infusion reactions, potential channelling, and potentially skewing economic incentives, there may be inherent biological differences in the safety and effectiveness profiles of the three drugs under study. Such differences have, however, been difficult to demonstrate beyond risks for uncommon safety outcomes. ${ }^{26} 27$ It remains unclear why we found an increased risk of discontinuation for adalimumab versus etanercept only during the 1 st year. It has been shown that development of adalimumab antidrug antibodies are associated with lower response and remission rates, while the clinical importance of etanercept antidrug antibodies is less clear. $^{28}{ }^{29}$ It has been reported that the percentage of patients developing antidrug antibodies increases at least over 3 years, and more than half of patients have been shown to develop them already over the first 24 weeks of treatment. ${ }^{28}$

\section{Strengths and limitations}

This study had a large sample size, long follow-up and data on multiple potential confounders. We also restricted our analysis to the period when all three drugs were available on the market, which is likely to influence drug survival. This was an observational study, reflecting the 'real world' experience in terms of drug survival in a nationwide setting covering an estimated $87 \%$ of all biologicals treated patients with RA. ${ }^{24}$

Without randomisation it is difficult to be certain that the observed differences are caused by inherent differences in the biochemical properties of the respective drugs. Patients with a different discontinuation risk may have been channelled to a specific drug, and we did find statistically significant (although numerically small) differences in patient characteristic between initiators of the different drugs. We adjusted for age, sex, education, clinical measures, disease duration, concomitant medication and general frailty, all of which were associated with the outcome. Residual confounding may still exist due to unknown and unmeasured channelling variables associated with the outcome. Removing the influence of such variables would require a randomised head-to-head trial.

The calendar period trends in patient characteristics, number of alternative treatment options available and changing expectations regarding treatment outcome make it imperative to conduct analyses accounting for potential differences by treatment initiation year when comparing different biological drugs. The threshold for discontinuation appears to have been lowered over time, as indicated by higher discontinuation rates and greater share of discontinuations being due to lack/loss of efficacy. A recent systematic review of biological discontinuation studies highlighted the need for a standardised failure definition to reduce the heterogeneity in future studies, but also noted that typical practice studies from registers likely need to rely on broader definitions. ${ }^{30}$ We relied on such a broad, nonstandardised failure definition in actual clinical care.

\section{CONCLUSION}

In this study, discontinuation rates were higher for infliximab compared with adalimumab and etanercept initiators, as well as for adalimumab versus etanercept initiators during the 1 st year. Discontinuation rates increased with calendar-period of TNFi initiation, as did the share of discontinuations due to inefficacy. At the end of the 5-year follow-up 38\% of infliximab, 50\% of adalimumab and $55 \%$ of etanercept initiators remained on their first drug.
Acknowledgements The authors would like to express their gratitude to all clinicians entering data into the Swedish Rheumatology Quality Register (including the Swedish Biologics Register ARTIS). For patient integrity protection purposes, all data were anonymised prior to delivery to the research group.

Collaborators The ARTIS Study Group: E Bäcklund (Uppsala University), L Cöster (Linköping University), H Forsblad-d'Elia (Sahlgrenska Academy), N Feltelius (Swedish Medical Products Agency), LE Kristensen (Lund University), L Jacobsson (Sahlgrenska Academy), L Klareskog (Karolinska Institutet), S Lindblad (Karolinska Institutet), S Rantapää-Dahlqvist (Umeå University), T Saxne (Lund University) and R van Vollenhoven (Karolinska Institutet).

Contributors This work was made on behalf of the ARTIS Study Group. Funding Astra Zeneca and Swedish Foundation for Strategic Research (SSF).

Competing interests This study was partly funded by the Swedish Foundation for Strategic Research (SSF), and by Astra Zeneca via the public private partnership COMBINE. Neither SSF nor Astra Zeneca had any influence on the study design, data acquisition, analysis, interpretation of the results or writing of the manuscript. Astra Zeneca representatives were allowed to comment upon the findings prior to submission although all final decisions resided with the investigators. The ARTIS Study Group conducts scientific analyses using data from the Swedish Biologics Register ARTIS run by the Swedish Society for Rheumatology. For the maintenance of this register, the Swedish Society for Rheumatology has received funding, independent of the conduct of these scientific analyses, from Schering-Plough, BMS, Wyeth, Abbott Laboratories, UCB and Roche.

Ethics approval Ethical approval was granted by the regional ethics committee at Karolinska Institutet, Stockholm, Sweden.

Provenance and peer review Not commissioned; externally peer reviewed.

Open Access This is an Open Access article distributed in accordance with the Creative Commons Attribution Non Commercial (CC BY-NC 3.0) license, which permits others to distribute, remix, adapt, build upon this work non-commercially, and license their derivative works on different terms, provided the original work is properly cited and the use is non-commercial. See: http://creativecommons.org/ licenses/by-nc/3.0/

\section{REFERENCES}

1 Du Pan SM, Dehler S, Ciurea A, et al. Comparison of drug retention rates and causes of drug discontinuation between anti-tumor necrosis factor agents in rheumatoid arthritis. Arthritis Rheum 2009;61:560-8.

2 Kievit W, Adang EM, Fransen J, et al. The effectiveness and medication costs of three anti-tumour necrosis factor alpha agents in the treatment of rheumatoid arthritis from prospective clinical practice data. Ann Rheum Dis 2008;67:1229-34.

3 Hyrich KL, Watson KD, Lunt M, et al. Changes in disease characteristics and response rates among patients in the United Kingdom starting anti-tumour necrosis factor therapy for rheumatoid arthritis between 2001 and 2008. Rheumatology (Oxford) 2011;50:117-23.

4 Simard JF, Arkema EV, Sundstrom A, et al. Ten years with biologics: to whom do data on effectiveness and safety apply? Rheumatology (Oxford) 2011;50:204-13

5 Gomez-Reino JJ, Rodriguez-Lozano C, Campos-Fernandez C, et al. Change in the discontinuation pattern of tumour necrosis factor antagonists in rheumatoid arthritis over 10 years: data from the Spanish registry BIOBADASER 2.0. Ann Rheum Dis 2012;71:382-5.

6 Kievit W, Fransen J, Adang EM, et al. Long-term effectiveness and safety of TNF-blocking agents in daily clinical practice: results from the Dutch Rheumatoid Arthritis Monitoring register. Rheumatology (Oxford) 2011;50:196-203.

7 Hetland ML, Christensen IJ, Tarp U, et al. Direct comparison of treatment responses, remission rates, and drug adherence in patients with rheumatoid arthritis treated with adalimumab, etanercept, or infliximab: results from eight years of surveillance of clinical practice in the nationwide Danish DANBIO registry. Arthritis Rheum 2010;62:22-32

8 Flendrie M, Creemers MC, Welsing PM, et al. Survival during treatment with tumour necrosis factor blocking agents in rheumatoid arthritis. Ann Rheum Dis 2003:62(Suppl 2):ii30-3.

9 Hjardem $\mathrm{E}$, Hetland ML, Ostergaard $\mathrm{M}$, et al. Prescription practice of biological drugs in rheumatoid arthritis during the first 3 years of post-marketing use in Denmark and Norway: criteria are becoming less stringent. Ann Rheum Dis 2005;64:1220-3

10 Hetland $\mathrm{ML}$, Lindegaard $\mathrm{HM}$, Hansen $\mathrm{A}$, et al. Do changes in prescription practice in patients with rheumatoid arthritis treated with biological agents affect treatment response and adherence to therapy? Results from the nationwide Danish DANBIO Registry. Ann Rheum Dis 2008;67:1023-6.

11 Soderlin MK, Geborek P. Changing pattern in the prescription of biological treatment in rheumatoid arthritis. A 7-year follow-up of 1839 patients in southern Sweden. Ann Rheum Dis 2008;67:37-42. 
12 Yazici Y, Krasnokutsky S, Barnes JP, et al. Changing patterns of tumor necrosis factor inhibitor use in 9074 patients with rheumatoid arthritis. J Rheumatol 2009;36:907-13.

13 Kristensen LE, Saxne T, Nilsson JA, et al. Impact of concomitant DMARD therapy on adherence to treatment with etanercept and infliximab in rheumatoid arthritis. Results from a six-year observational study in southern Sweden. Arthritis Res Ther 2006;8:R174.

14 Heiberg MS, Koldingsnes W, Mikkelsen K, et al. The comparative one-year performance of anti-tumor necrosis factor alpha drugs in patients with rheumatoid arthritis, psoriatic arthritis, and ankylosing spondylitis: results from a longitudinal, observational, multicenter study. Arthritis Rheum 2008;59:234-40.

15 Marchesoni A, Zaccara E, Gorla R, et al. TNF-alpha antagonist survival rate in a cohort of rheumatoid arthritis patients observed under conditions of standard clinical practice. Ann NY Acad Sci 2009;1173:837-46.

16 Brocq 0, Roux $\mathrm{CH}$, Albert C, et al. TNFalpha antagonist continuation rates in 442 patients with inflammatory joint disease. Joint Bone Spine 2007;74:148-54.

17 Geborek P, Crnkic M, Petersson IF, et al. Etanercept, infliximab, and leflunomide in established rheumatoid arthritis: clinical experience using a structured follow up programme in southern Sweden. Ann Rheum Dis 2002;61:793-8.

18 Zink A, Listing J, Kary S, et al. Treatment continuation in patients receiving biological agents or conventional DMARD therapy. Ann Rheum Dis 2005;64:1274-9.

19 Duclos M, Gossec L, Ruyssen-Witrand A, et al. Retention rates of tumor necrosis factor blockers in daily practice in 770 rheumatic patients. J Rheumatol 2006;33:2433-8.

20 Greenberg JD, Reed G, Decktor D, et al. A comparative effectiveness study of adalimumab, etanercept and infliximab in biologically naive and switched rheumatoid arthritis patients: results from the US CORRONA registry. Ann Rheum Dis 2012;71:1134-42.
21 Neovius M, Sundstrom A, Simard J, et al. Small-area variations in sales of TNF inhibitors in Sweden between 2000 and 2009. Scand J Rheumatol 2011;40:8-15.

22 Neovius M, Simard JF, Askling J. Nationwide prevalence of rheumatoid arthritis and penetration of disease-modifying drugs in Sweden. Ann Rheum Dis 2011;70: 624-9.

23 Askling J, Fored CM, Geborek P, et al. Swedish registers to examine drug safety and clinical issues in RA. Ann Rheum Dis 2006;65:707-12.

24 Neovius M, Simard J, Sundstrom A, et al. Generalisability of clinical registers used for drug safety and comparative effectiveness research: coverage of the Swedish Biologics Register. Ann Rheum Dis 2011;70:516-19.

25 Weaver AL, Lautzenheiser RL, Schiff MH, et al. Real-world effectiveness of select biologic and DMARD monotherapy and combination therapy in the treatment of rheumatoid arthritis: results from the RADIUS observational registry. Curr Med Res Opin 2006;22:185-98

26 Gartlehner G, Hansen RA, Jonas BL, et al. The comparative efficacy and safety of biologics for the treatment of rheumatoid arthritis: a systematic review and metaanalysis. J Rheumatol 2006;33:2398-408.

27 Donahue KE, Gartlehner G, Jonas DE, et al. Systematic review: comparative effectiveness and harms of disease-modifying medications for rheumatoid arthritis. Ann Intern Med 2008;148:124-34.

28 Bartelds GM, Krieckaert CL, Nurmohamed MT, et al. Development of antidrug antibodies against adalimumab and association with disease activity and treatment failure during long-term follow-up. JAMA 2011;305:1460-8.

29 Krieckaert CL, Jamnitski A, Nurmohamed MT, et al. Comparison of long-term clinical outcome with etanercept treatment and adalimumab treatment of rheumatoid arthritis with respect to immunogenicity. Arthritis Rheum 2012;64:3850-5.

30 Yoshida K, Sung YK, Kavanaugh A, et al. Biologic discontinuation studies: a systematic review of methods. Ann Rheum Dis 2014;73:595-9. 